OPEN ACCESS

Edited by:

Davide Settembre Blundo,

Rey Juan Carlos University, Spain

Reviewed by:

Harrison Lourenço Corrêa,

Federal University of Paraná, Brazil

Marco Vacchi,

University of Modena and Reggio

Emilia, Italy

*Correspondence:

Dongwon K

dongwonk@sit.re.kr

Han Jin Oh

ohj@sit.re.kr

Specialty section:

This article was submitted to

Circular Economy,

a section of the journal

Frontiers in Sustainability

Received: 11 August 2021

Accepted: 31 August 2021

Published: 27 September 2021

Citation:

Ki D, Kang SY, Ma G and Oh HJ (2021) Application of Waste Plastic

Films in Road Infrastructure and

Construction.

Front. Sustain. 2:756723

doi: 10.3389/frsus.2021.756723

\section{Application of Waste Plastic Films in Road Infrastructure and Construction}

\author{
Dongwon $\mathrm{Ki}^{1 *}$, Shin Young Kang ${ }^{1}$, Gyeonghoon $\mathrm{Ma}^{2,3}$ and $\mathrm{Han}$ Jin $\mathrm{Oh}^{2 *}$ \\ ${ }^{1}$ Division of Living and Built Environment Research, Seoul Institute of Technology, Seoul, South Korea, ${ }^{2}$ Division of Urban \\ Infrastructure Research, Seoul Institute of Technology, Seoul, South Korea, ${ }^{3}$ Department of Civil Engineering, Inha University, \\ Incheon, South Korea
}

Recycling waste synthetic resins, including rigid and film plastics, is a pressing issue worldwide due to the issues associated with waste treatment. Using products originating only from plastic wastes could be a promising way to improve the waste recycling rate and address plastic consumption. This study presents the applications of waste plastic films (WPFs) in urban infrastructure and construction materials, especially bearing loads. WPF-recycled products (WPF-RPs) were evaluated for mechanical properties, including strength (compressive and tensile), thermal expansion coefficient, accelerated weathering, dynamic stability, and environmental aspects, such as the presence of hazardous substances. Subsequent tests confirmed moderate strength, good weathering stability against solar irradiation, and superior road pavement vehicle load through wheel-tracking tests compared with the standards for asphalt. Additionally, hazardous substances were mostly not detected or were under permissible limits in the composition and leachate contents of WPF-RPs. After using temporary pavement blocks (TPBs) from WPFs at a field site for one month, we conducted slip resistance tests which gave a result of $\sim 33$ British pendulum number, indicating the possible application of WPF-RPs in low-speed driving sections, according to the Korean standards of the Ministry of Land, Infrastructure and Transport. Moreover, it was confirmed that fastening structures installed between the TPBs can improve backfilling and compaction defects. This practical research highlights the possible applications of products produced from WPFs for infrastructure development, such as filling materials for burial pipes or tubes; however, these potential aspects should be tested further.

Keywords: synthetic resin, temporary pavement block, pothole emergency repair, backfilling structure, underground buried pipe, recycling, upcycling, waste-to-resource

\section{INTRODUCTION}

Since the development of plastic (or synthetic resin) in the 1950s, its advantages, such as economic price, light weight, and resistance to heat and corrosion, have resulted in the exponential growth in the use of plastic products and generation of plastic wastes, especially by following the conventional "take-make-dispose" linear material flow economic model (Geyer et al., 2017; Horodytska et al., 2018). Approximately 370 million tons of plastic products were produced in 2019 globally (PlasticsEurope, 2020), and the annual plastic production is expected to increase consistently to 1,800 million tons by 2050 (Ryan, 2015). In Korea, the domestic demand for plastics was 4.0 million tons in 2019 (Ministry of Environment (MOE), 2020a). Global statistics show that waste plastics 
are generally discharged into the natural environment or end up in landfills $(79 \%)$ or are subjected to incineration $(12 \%)$ or recycling (9\%) treatment methods (Geyer et al., 2017). Among the multiple applications of plastics, the packaging sector shows the highest use of plastics in the world (36\%), Japan (41\%), and Korea (47\%), followed by the building and construction $(12-16 \%)$, textile $(14 \%)$, and transportation sectors $(7-12 \%)$ (Geyer et al., 2017; Jang et al., 2020). Plastics used for packaging are typically thin and are called "plastic films." They are suitable only for a single use. Thus, treating large quantities of waste plastic films (WPFs; plastic flexible films or waste vinyl) is a pressing issue worldwide. WPF utilization as a waste treatment method is also an important topic in United Nations Sustainable Development Goal 12 ensuring sustainable consumption and production to reduce the use of natural resources and manage the lifecycle of plastics (UN, 2016; De Souza, 2019).

Recycling methods of waste plastics, including WPFs, are largely classified into four types: closed-loop, downcycling (or open-loop, downgrading), molecular recycling (or chemical recycling), and energy recovery (Hopewell et al., 2009). Primary recycling is called material or mechanical recycling, which includes closed-loop and open-loop processes. These processes differ in the recyclate quality. The closed-loop recycling process produces a recyclate with a quality similar to that of virgin material from waste plastics, which are single or monolayer plastics, whereas the open-loop recycling process applies products of a lower grade or less demanding products with multilayer plastics along with contaminants, such as additives or inks. Chemical or molecular recycling converts plastics to valuable commodity chemicals through thermal and chemical processes, such as pyrolysis, depolymerization, and partial oxidation (Hamad et al., 2013; Horodytska et al., 2018). Although monomer separation technology has recently been developed, the debate on the environmental and economic benefits of chemical recycling is ongoing, mainly due to the technical developmental status and competitiveness of commercially available virgin chemicals (Shen et al., 2010; Geyer et al., 2017; Rahimi and García, 2017; Meys et al., 2020). The energy recovery method can produce electricity and supply heat from incineration. Despite its advantage of large volume reduction of plastic wastes, environmental issues still exist, such as the release of greenhouse gases and pollutants. Moreover, this method contrasts with the principles of circular economy, which emphasizes on reuse and recycling; additionally, compared with mechanical recycling, energy recovery has approximately 1.7 times less heating value for plastics $\left(60,000 \mathrm{~kJ} \mathrm{~kg}^{-1}\right.$ vs. $36,000 \mathrm{~kJ} \mathrm{~kg}^{-1}$ ) (Rahimi and García, 2017).

The above-mentioned recycling methods are associated strongly with the type and quality (or purity) of the WPFs, which are assessed during the collection of WPFs, and sorting and treatment of recyclate or final recycling products. The WPFs from households (or generated after end-use) are a mixture of different polymer types and multilayers that are contaminated

Abbreviations: WPF, waste plastic film; TPB, temporary pavement block; BPN, British pendulum number; WPF-RP, waste plastic film-recycled product. with additives, coatings, or inks (Horodytska et al., 2018). They have been used to make solid refuse fuel in Korea for energy recovery since 2013 during the implementation of the new renewable energy supply obligation system or renewable portfolio standard. Moreover, the revision of the "Act on the Promotion of Saving and Recycling of Resources" provided an opportunity to actively use waste because it was classified as a general solid fuel product (Ministry of Environment (MOE), 1992). However, in 2020, the policy changed with the renewable energy certificate weights of non-renewable solid refuse fuel reduced to zero, implying that solid refuse fuel made from plastic wastes or WPFs can no longer classified as renewable energy sources (Ministry of Trade, Industry and Energy (MOTIE), 2019; Joo and Yeo, 2020). Thus, at present, the material recycling rate of WPFs is a better alternative than recycling through energy recovery from incineration in South Korea.

Previous studies on material recycling of WPFs or rigid plastics have shown that waste plastics can be used in construction materials by mixing them with conventional materials, such as coarse aggregates for asphalt and cement (Kim et al., 2013, 2020; Yeom et al., 2014; Korea Institute of Construction Technology (KICT), 2018). In addition, the physicochemical properties of WPF-derived products have not been systematically studied, and thus, details on the WPF applicability to construction materials are limited (Chung et al., 2013; Dahlbo et al., 2018). Another practical study attempted to produce street tree guards with WPF only (Ministry of Environment (MOE), 2020b), but testing for load-bearing construction structures has not been conducted. In this study, we aimed to assess the mechanical and environmental characteristics of WPF-recycled products (WPF-RPs) for construction applications, specifically temporary pavement blocks (TPBs), for outdoor environmental conditions. Prototype demonstration tests were also conducted for (i) slip resistance to determine which areas were acceptable for the WPF-RP TPB and (ii) the effect of fastening structures installed between the TPBs to determine whether backfilling and compaction defects could be enhanced. Moreover, we suggest other applications of WPF-RPs based on the results of mechanical and environmental characteristics and prototype demonstrations.

\section{MATERIALS AND METHODS}

\section{Manufacturing Procedure of Recycled Products for Road Infrastructure and Construction Application and Specimens for Physical Characteristics}

The WPF-RPs required for TPBs were produced and provided by a manufacturing company in Korea, which has facilities for visual sorting, magnetic sorting, high-rate shredding, melting, and compression molding. The company produces products such as street tree guards and vegetation mats (Ministry of Environment (MOE), 2020b). The dominant type of WPF from household wastes was polyethylene. TPB prototypes, with dimensions 0.3 $(\mathrm{W}) \times 0.3(\mathrm{~L}) \times 0.125(\mathrm{D}) \mathrm{m}$, were produced using a newly 
designed mold. A picture of the TPB unit is provided in Supplementary Figure S1.

\section{Mechanical Characteristics of Waste Plastic Film-Recycled Products}

Test specimens were prepared from the WPF-RPs, depending on the standard size. Mechanical properties of WPF-RPs as construction materials, were measured and evaluated, including compressive and tensile strengths, compressive and tensile elasticities, Poisson's ratio, density, and coefficient of thermal expansion. Seven specimens each were prepared for testing the compressive strength, compressive elastic modulus, tensile strength, tensile elastic modulus, and Poisson's ratio, while five specimens each were prepared for density and thermal expansion measurements. The tests were conducted according to the procedures given by the Korea Standard Methods (Korean Industrial Standards, KS M ISO 11359-2, 2017; Korean Industrial Standards, KS M ISO 527, 2017; Korean Industrial Standards, KS M ISO 604, 2018; Korean Industrial Standards, KS M ISO 1183-1, 2019) and are summarized in Supplementary Table S1; Supplementary Figure S2.

\section{Accelerated Weathering Tests of Waste Plastic Film-Recycled Products}

Accelerated weathering tests were performed to investigate the weathering effect of the WPF-RPs and the deterioration of physical characteristics of WPF-RP TPBs during long-term application in an external environment. Three specimens with dimensions of $7(\mathrm{~W}) \times 15(\mathrm{~L}) \times 1$ (D) $\mathrm{cm}$ were prepared by cutting WPF-RPs and commercial high-density polyethylene (HDPE) samples purchased from Polypenco Korea to compare the weathering performance between new and recycled materials. Xenon lamps (Ci4000, ATLAS) were used with an S-borosilicate (S-boro) filter, black panel temperature of $63 \pm$ $3^{\circ} \mathrm{C}$, relative humidity of $50 \pm 5 \%$, and irradiance condition of $0.51 \mathrm{~W} / \mathrm{m}^{2}$ at $340 \mathrm{~nm}$ for the accelerated weathering test following the instructions given in Korean Industrial Standards, KS F 2274: 2018 (2018). The simulation cycle was irradiated for $102 \mathrm{~min}$, with exposure to water for $18 \mathrm{~min}$ in a weathering chamber. Accelerated weathering tests were conducted for up to $1,500 \mathrm{~h}$ at an increment of $500 \mathrm{~h}$. The conversion of irradiation time in the weathering chamber to accelerated weathering time was calculated using the 10-year average value of horizontal solar insolation in Seoul by assuming approximately $5 \%$ of ultraviolet irradiation and excluding humidity and temperature; that is, the weathering time in the accelerated weathering test chamber was calculated to be $\sim 1,500 \mathrm{~h}(540 \mathrm{~d})$. These calculations were conducted according to the methods given by Gewert et al. (2018), and further details are provided in Supplementary Table S2. Later, surface cracking and color variation (CE7000A, x-rite) were tested following Korean Industrial Standards, KS A 0063: 2015 (2015). Tensile strength, and elongation at break were measured following Korean Industrial Standards, KS M ISO 527-2 (2018) (RTF series Tensilon, A\&D). Color difference was measured and calculated using the following equation from a previous study (Mokrzycki and Tatol, 2011):

$$
\Delta E_{a b}^{*}=\sqrt{\left(L_{1}^{*}-L_{2}^{*}\right)^{2}+\left(a_{1}^{*}-a_{2}^{*}\right)^{2}+\left(b_{1}^{*}-b_{2}^{*}\right)^{2}}
$$

Here, $\mathrm{L}^{*}, \mathrm{a}^{*}$, and $\mathrm{b}^{*}$ indicate the lightness (black/white), red and green between +127 and -128 , and blue and yellow between +127 and -128 , respectively, and the subscripts 1 and 2 represent the values of the starting point at time zero and at the irradiation times $(500,1,000$, and $1,500 \mathrm{~h})$ during the accelerated weathering test.

\section{Dynamic Stability Assessment}

Dynamic stability of construction materials from the WPFRP samples was assessed by the wheel-tracking test (AI-11003, Iwata, Japan) following Korean Industrial Standards, KS F

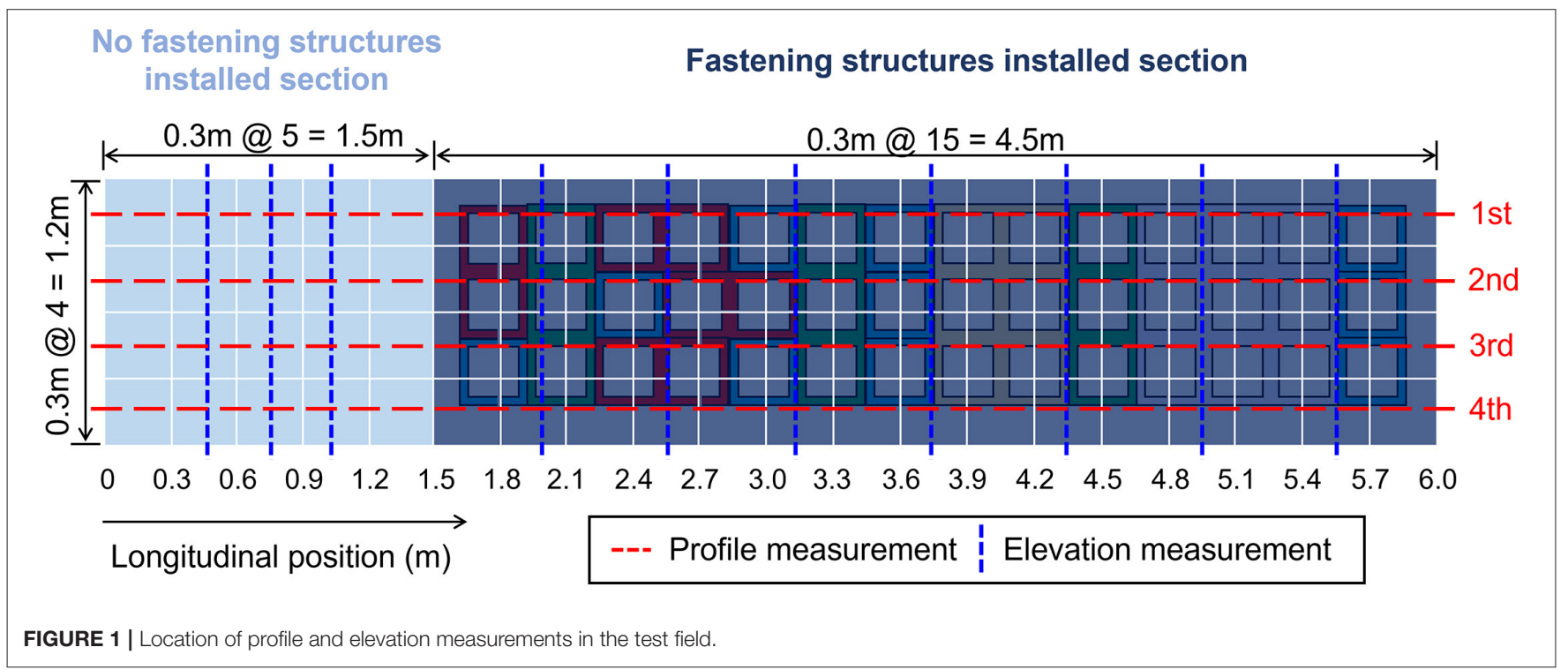


TABLE 1 | Results of physical characteristics of WPF-RPs as construction materials.

\begin{tabular}{|c|c|c|}
\hline & WPF & Concrete \\
\hline Compressive strength (MPa) & $37.8( \pm 0.8)$ & $\begin{array}{l}\text { 31-45 [Han et al. (2003), Lam et al. (2018), and Aghaeipour and Madhkhan } \\
\text { (2020)] }\end{array}$ \\
\hline Compressive elasticity (MPa) & $844( \pm 42)$ & $\begin{array}{l}\text { 25,000-30,000 [You and Sim (2006), Noguchi et al. (2009), Lim et al. } \\
\text { (2010), and Park et al. (2017)] }\end{array}$ \\
\hline Tensile strength (MPa) & $14.4( \pm 1.9)$ & - \\
\hline Tensile elasticity (MPa) & $781( \pm 12)$ & - \\
\hline Poisson's ratio (-) & $0.38( \pm 0.03)$ & - \\
\hline Density $\left(\mathrm{g} / \mathrm{m}^{3}\right)$ & $0.983( \pm 0.003)$ & 2.4 [Han et al. (2003), and Lim et al. (2010)] \\
\hline Coefficient of thermal expansion $\left(\mu \mathrm{m} / \mathrm{m} \cdot{ }^{\circ} \mathrm{C}\right)$ & $122.7( \pm 1.4)$ & 10 [Lim et al. (2010), and Park et al. (2017)] \\
\hline
\end{tabular}

WPF-RP, waste plastic film-recycling products.

TABLE 2 | Results of the accelerated weathering test on WPF-RP and HDPE samples.

\begin{tabular}{|c|c|c|c|c|}
\hline Accelerated weathering time & $\mathbf{O h}$ & $500 \mathrm{~h}$ & $1,000 \mathrm{~h}$ & $1,500 \mathrm{~h}$ \\
\hline \multicolumn{5}{|l|}{ WPF-RP samples } \\
\hline Color difference & - & $5.15( \pm 0.88)$ & $5.33( \pm 1.83)$ & $5.34( \pm 2.62)$ \\
\hline \multicolumn{5}{|l|}{ HDPE samples } \\
\hline Color difference & - & $0.86( \pm 0.12)$ & $0.97( \pm 0.13)$ & $1.03( \pm 0.19)$ \\
\hline
\end{tabular}

HDPE, high-density polyethylene.

2374: 2017 (2017). The wheel-tracking test is a representative method for evaluating the resistance of a specimen to plastic deformation, mostly in summer, by mimicking indoor sites and passing actual vehicle loads under high-temperature of pavement conditions. Specimens with a size of $300 \times 300 \times 50 \mathrm{~mm}$ were prepared and tested with $686 \mathrm{~N}$ ( or $628 \mathrm{kPa}, 70 \mathrm{~kg}$ ) of wheel load at a rate of 42 cycles/min (i.e., 2,520 cycles/ $60 \mathrm{~min}$ ) at $60^{\circ} \mathrm{C}$. Deformations at 15, 30, 45, and $60 \mathrm{~min}$ for the six test specimens were measured, and dynamic stabilities were calculated using the following equation:

$$
\text { Dynamic stability }=42 \times \frac{t_{2}-t_{1}}{d_{2}-d_{1}} \times C
$$

Here, 42 represents the number of repeated cycles per $1 \mathrm{~min}$, $\mathrm{d}_{1}$ and $\mathrm{d}_{2}$ are the displacements of deformations $(\mathrm{mm})$ at $t_{1}=$ $45 \mathrm{~min}$ and $t_{2}=60 \mathrm{~min}$, respectively, and $\mathrm{C}$ is the correction factor of the test machine type, where the value of $\mathrm{C}$ is 1.0 because the crank connecting link drives the test specimens.

\section{Field Tests for Temporary Pavement Block}

To apply the TPB prototype using WPF-RPs, field tests were performed at a site in Seoul, which experienced frequent traffic from heavy vehicles, thereby simulating a real road site. The size of the field was $1.2 \mathrm{~m}(\mathrm{~W}) \times 6 \mathrm{~m}$ (L) and could accommodate $80 \mathrm{WPF}-\mathrm{RP}$ prototype units, as shown in Figure 1. Further, the total $6 \mathrm{~m}$ length of the test site was divided into $4.5 \mathrm{~m}$ and $1.5 \mathrm{~m}$ sections with and without installing fastening structures, which were designed to improve the load transferability and equalization between blocks (Supplementary Figures S1, S3) to evaluate the scalability of the TPBs in road pavement construction sites. Before and after one month of the operation of the WPF-RP TPBs, profiles, elevation, and slip (or skid) resistance were measured at the installed test site. The profiles of the four rows $(1 \mathrm{st}-4$ th) were measured three times each along the longitudinal direction of the installed TPBs (Figure 1) using a Surf-Pro walking profiler (CS8850, Surface Systems \& Instruments, Inc. USA). The profiles were not used to measure absolute displacement, but relative displacement based on the starting point of the TPBs, which was considered to be $0 \mathrm{~mm}$. The elevations at certain locations in the middle of each TPB 
(Figure 1) were measured using a bar ruler and a $30 \mathrm{~cm}$-stainless steel ruler. To mimic the sliding of a vehicle, a standard slip resistance test was conducted with a British pendulum number (BPN) tester (HM-602W, Gilson, USA) following the method of Korean Industrial Standards, KS F 2375 (2016), similar to ASTM E 303.

\section{Environmental Assessment of Hazardous Substances}

The contents and leachate characteristics of hazardous substances, including heavy metals, from the WPFs, prototype samples were analyzed following the IEC 62321 and Korean Official Wastes Test Method, respectively
(Ministry of Environment (MOE), 2017). Among the contents of 10 hazardous substances regulated by the Act on Resource Circulation of Electrical and Electronic Equipment and Vehicles (Ministry of Environment (MOE), 2019), which was recently updated following the Restriction of Hazardous Substances II directive (Directive 2011/65/EU, 2011), Pb and Cd were measured using inductively coupled plasma-optical emission spectrometry (Optima 8300DV, PerkinElmer, UK), $\mathrm{Hg}$ was measured using a mercury analyzer (FIMS 400, PerkinElmer, UK), $\mathrm{Cr}^{6+}$ was measured using ultraviolet/ visible spectrophotometer (V530, Jasco, JP), polybrominated biphenyls and polybrominated diphenyl ethers were measured using gas chromatography-mass spectrometry (7975, Agilent, US), and bis (2-ethylhexyl) phthalate, benzyl butyl phthalate, dibutyl phthalate, and diisobutyl phthalate were measured using gas chromatography-mass spectrometry (5977B, Agilent, US).

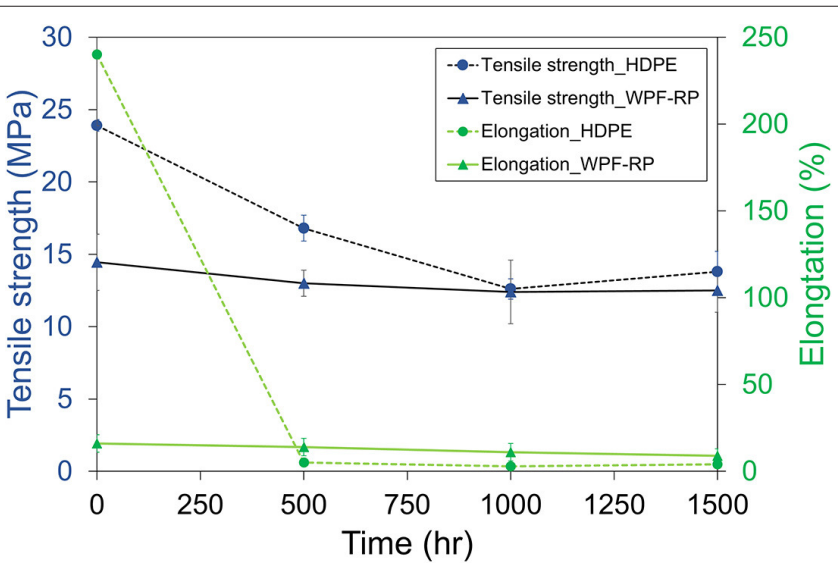

FIGURE 2 | Variations in the tensile properties of the WPF-RP and HDPE samples during accelerated weathering test. Standard deviations for both tensile strength and elongation tests are presented (six tests each were performed for tensile strength and elongation).

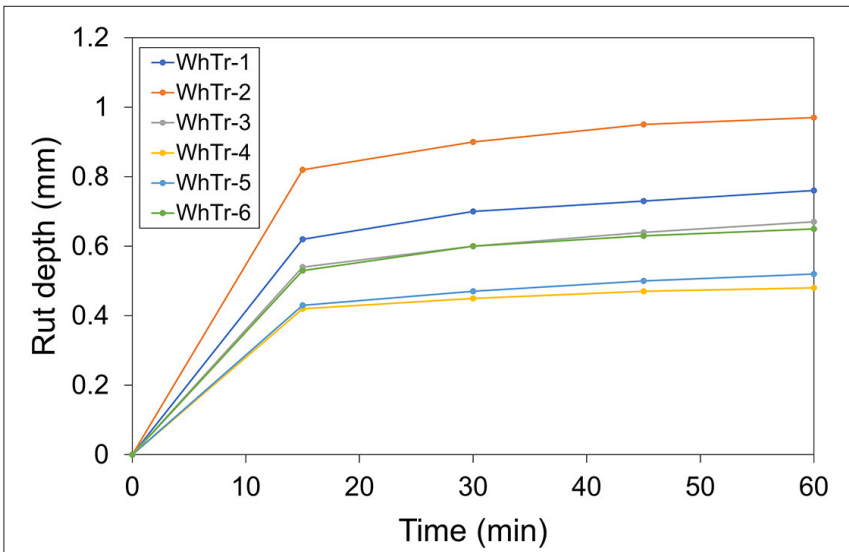

FIGURE 3 | Results of rut depth vs. time in wheel-tracking tests for six WPF samples.
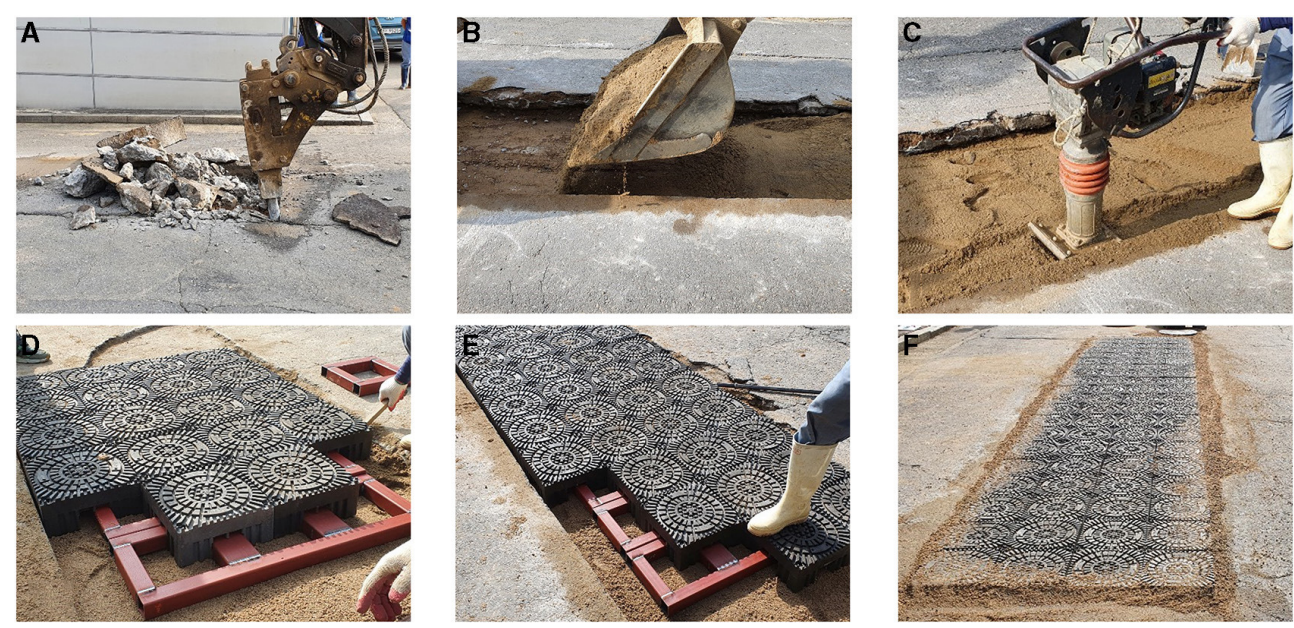

FIGURE 4 | Construction of the field test for TPB application: (A) excavation, (B) refilling, (C) compaction, (D) initiation of TPB construction, (E) TPB construction expansion, and (F) TPB construction completion. 
Samples for the leachate tests of 11 hazardous substances listed in the Korean Official Wastes Test Method were pretreated with an acid solution. $\mathrm{Cr}^{6+}, \mathrm{Cu}, \mathrm{Cd}, \mathrm{Pb}$, and As were measured using inductively coupled plasma-optical emission spectrometry (Optima 5300DV, PerkinElmer, UK), Hg was measured by atomic absorption spectrometry (FIMS 100, PerkinElmer, UK), cyanide was measured using an ultraviolet/ visible spectrophotometer (V530, Jasco, JP), organophosphorus compounds were measured by gas chromatography-nitrogen phosphorous detector $(6890 \mathrm{~N}$, Agilent, US), tetrachloroethylene and trichloroethylene were measured by gas chromatography with a microelectron capture detector (7890A, Agilent, US), and oil was measured by gravimetry after extraction with hexane.

\section{RESULTS}

\section{Mechanical Properties of the Waste Plastic Film-Recycled Products for Construction Application}

The mechanical characteristics of the WPF-RPs are shown in Table 1. The standard deviations of all the measured parameters were small, indicating the homogeneity of the materials. The compressive strength of the WPF-RP samples was approximately $38 \mathrm{MPa}$, which is close to that of cement concrete (Han et al., 2003; Lam et al., 2018; Aghaeipour and Madhkhan, 2020), indicating that rigidity was comparatively excellent. As the compressive strength was $\sim 2.3$ times greater than the tensile strength, using the WPF-RPs as a compression member rather than a tensile member is advantageous in terms of the construction material performance. However, in the compression test, the elasticity was approximately 32-38 times smaller than that of concrete, which can cause significant deformation during load application, thus making it inappropriate for use as a supporting structure during major loads. In addition, the coefficient of thermal expansion was $\sim 12$ times more than that of concrete; therefore, replacing existing construction materials would be difficult in poor environments, such as those with a large annual temperature difference, depending on the weather conditions, exposure to the external environment, and load conditions.

\section{Stability Under External Light Exposure Condition}

The changes in appearance after the accelerated weathering test for the WPF-RPs and commercial HDPE samples are shown in Table 2. No significant change was observed in the appearance of the two plastic specimens until 1,500 h, which corresponded to $540 \mathrm{~d}$; additionally, no cracks were observed. The original color of the HDPE was opaque white, and no visible color change was observed. However, for the WPFRP specimens, the light-exposed areas became brighter with increasing exposure times. The color difference was measured quantitatively before and after the accelerated weathering test, with marginally increased values after $500 \mathrm{~h}$ in both samples. Although a standard for changes in elevation $(\Delta \mathrm{E})$ does not
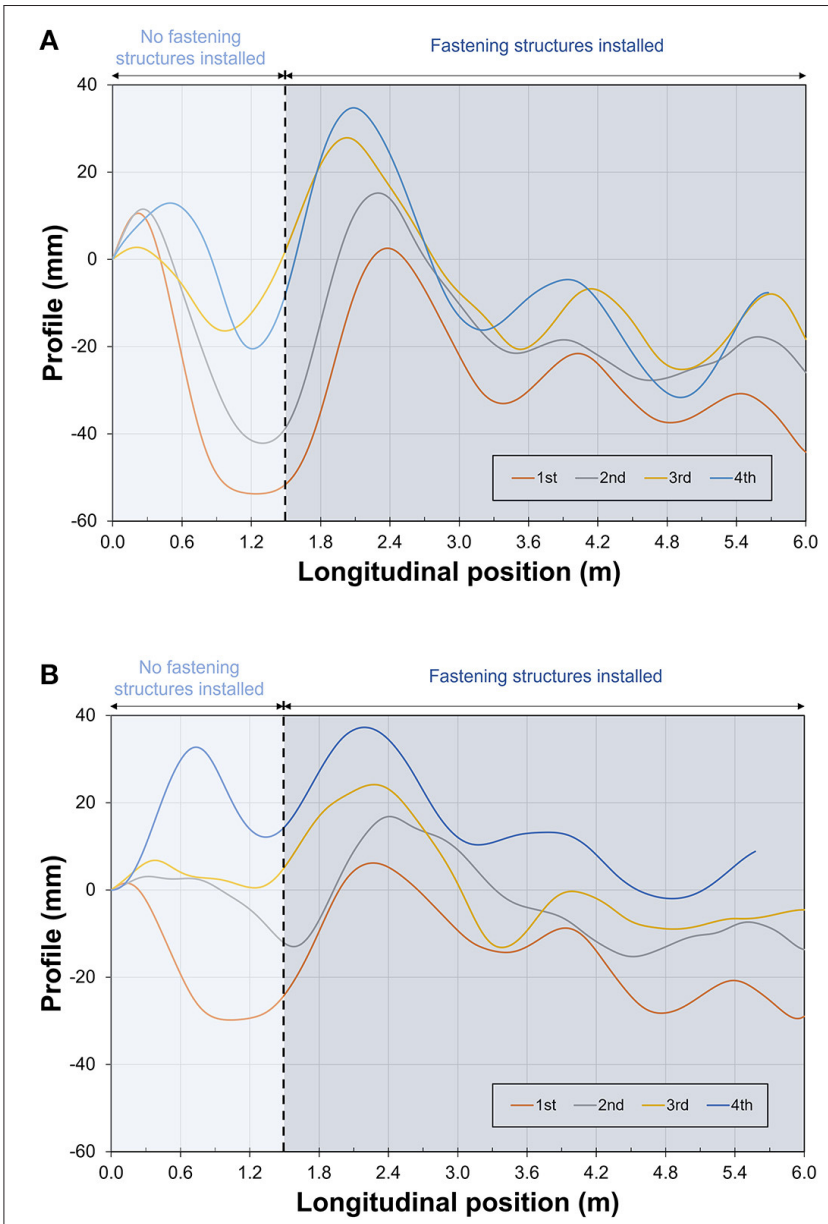

FIGURE 5 | Profiles measured in longitudinal directions with and without the installation of fastening structures: (A) immediately after construction and (B) one month after construction. Measurements of four rows in longitudinal directions are indicated by 1 st -4 th in the graphs.

exist, a color difference was observed when its value exceeded 1 , and the color difference increased with the increase in its value. The values for HDPE samples were close to 1 , whereas those for WPF-RP samples were approximately five times higher (5.3).

After the accelerated weathering tests, we assessed the tensile properties of strength and elongation at breaks (Figure 2). A significant decrease in the values for the HDPE samples was observed over time compared with the samples that were not weathered. Conversely, the values for the WPF-RP samples were constant throughout the testing time up to $1,500 \mathrm{~h}$. Although the tensile characteristics of the WPF-RPs are lower than those of pure plastic before weathering and photo-aging, the tensile strength and elongation of the WPF-RPs could be compared with those of HDPE samples after $500-1,000 \mathrm{~h}$, possibly because of the complex structure of the composite polymers in the WPF-RPs (Shah et al., 2008; Iñiguez et al., 2018). 


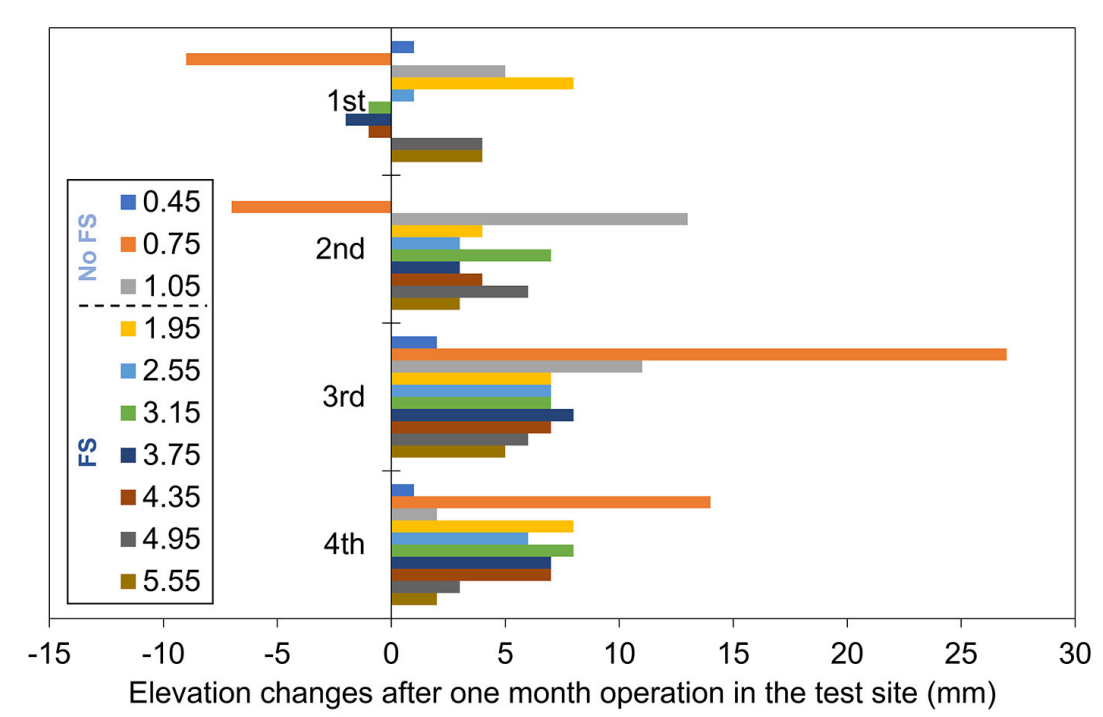

FIGURE 6 | Elevation changes (or $\Delta$ elevation) monitored at the test sites. Positive values indicate ground settlement, while negative values indicate ground heave. Numbers in the legend are the position of longitudinal direction in the test site as shown in Figure 1. "No FS" and "FS" indicate conditions without and with fastening structures installed, respectively.

\section{Stability of Road Pavement Vehicle Load}

In addition to the mechanical properties, WPF-RPs should ideally show good stability under vehicle loads in road pavement. Thus, wheel-tracking tests were performed to evaluate the stability of vehicle loads on road pavements. Figure 3 shows that the rut depth values for six samples varied due to material heterogeneity, and the dynamic stabilities ranged from 21,000 to 63,000 cycles $/ \mathrm{mm}$ with an average of $33,250 \pm 15,456$ cycles/mm. This indicates that the dynamic stability of the WPFRPs was much higher than that of the asphalt quality standards generally used for road pavement $(>3,000$ for flow resistance, 2,000-3,000 for stone mastic asphalt, $>2,500$ for drainage, and $>750$ for emergency repair at room temperature) (Ministry of Land, Infrastructure and Transport (MOLIT), 2017). These high stability values acquired through the wheel-tracking tests for the WPF-RPs, compared with those of general asphalt pavements, and verified the dynamic stability of the vehicle load while using WPF-RPs as road pavement materials. Therefore, this study provided a better alternative measure to effectively apply WPFRPs in construction.

\section{Environmental Assessment of the Waste Plastic Film-Recycled Products}

The application of wastes, including WPFs, as recycling resources, require environmental assessment, because the wastes may contain various hazardous substances. Synthetic resin products, such as plastic films, comprise petroleum-based synthetic resins and additives, such as plasticizers, heat stabilizers, and antioxidants that are added in the manufacturing process (Rahimi and García, 2017; Dahlbo et al., 2018). Thus, while using WPF-RPs, these substances may be released to the environment, subsequently affecting environmental quality and human health.
Environmental safety criteria differ depending on the usage of products from waste. The 10 restricted materials in the WPFRPs given by the Restriction of Hazardous Substances II were analyzed. Among these, seven were not detected, and three were within the permissible limits, that is, $19.3 \mathrm{mg} / \mathrm{kg}$ of $\mathrm{Pb}(<1,000$ $\mathrm{mg} / \mathrm{kg}), 1.2 \mathrm{mg} / \mathrm{kg}$ of $\mathrm{Cd}(<100 \mathrm{mg} / \mathrm{kg})$, and $732 \mathrm{mg} / \mathrm{kg}$ of bis (2-ethylhexyl) phthalate $(<1,000 \mathrm{mg} / \mathrm{kg})$. Additionally, only $\mathrm{Cu}$ $(0.013 \mathrm{mg} / \mathrm{L})$ was detected among the 11 hazardous substances by testing the leachates of WPF-RPs. The concentration of $\mathrm{Cu}$ was two times lower than the permissible limit $(<3 \mathrm{mg} / \mathrm{L})$, which is used to classify "Designated Waste" as defined in the Korean Official Wastes Test Method (Ministry of Environment (MOE), 2017).

\section{Evaluation of the Field Performance of the Waste Plastic Film-Recycled Products}

Figure 4 shows the process of using WPF-RP TPBs at the test site, which started with excavation for the designated size of the field test, with dimensions of $1.2 \mathrm{~m}(\mathrm{~W}) \times 6 \mathrm{~m}$ (L) for 80 WPF-RP prototype units, to simulate real road construction.

We performed field tests of TPBs at the site, with frequent heavy vehicular traffic for one month, and inspected for any appearance of damage, such as breakage or cracking. Figure 5 shows the longitudinal profile measurement results of the WPFRP TPB installation section. The profile change after one month of the test showed no significant difference in the section installed with the fastening structures; however, each column was displaced individually, and a change in the slope was observed in the four columns of the section lacking the fastening structures. However, the profile changes, regardless of the installation of the fastening structures, showed increments in slope of $30 \mathrm{~cm}$, which is the TPB unit size. Therefore, the 


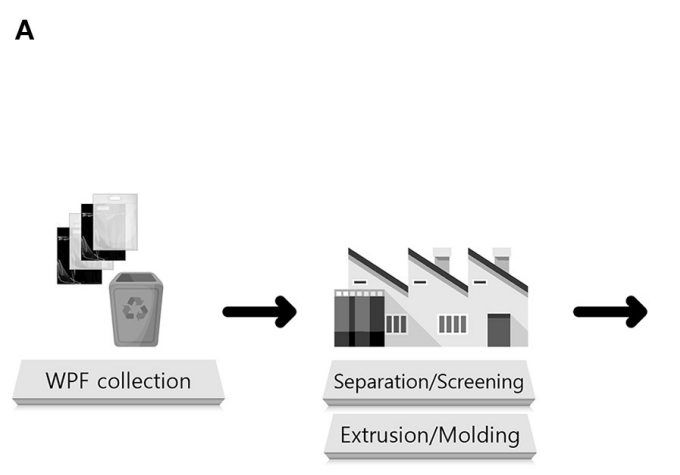

B

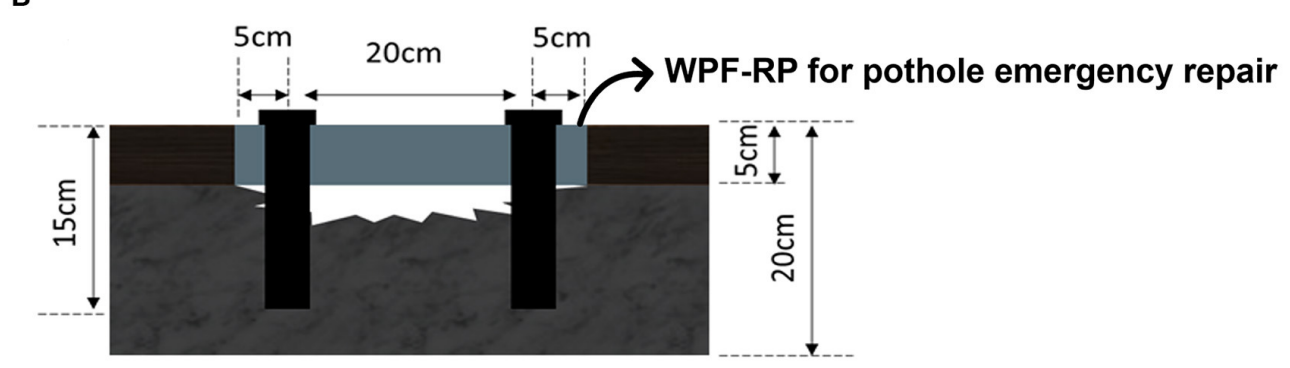

C

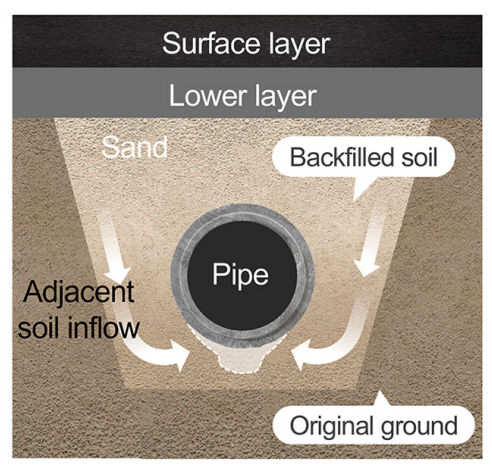

WPF-RP for pothole emergency repair

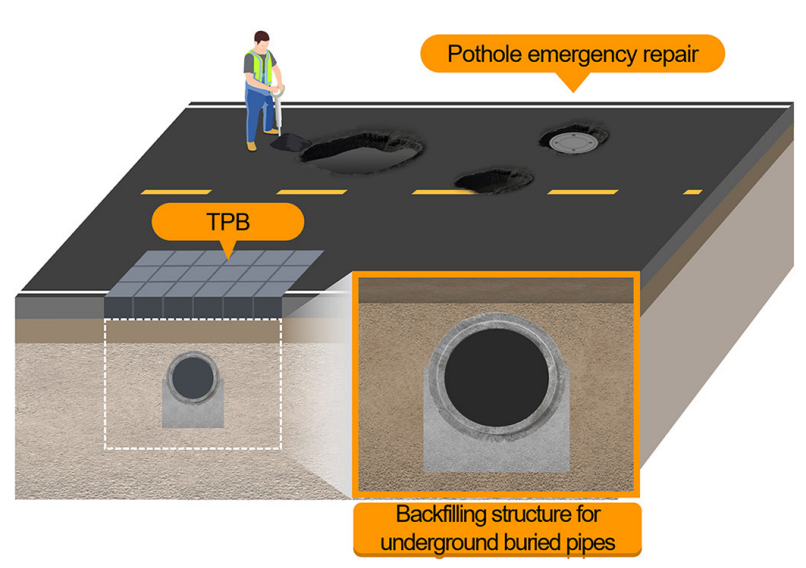
FIGURE 7 | Application of WPF-
for underground buried pipe.

TPB flatness after compaction and before TPB installation would have probably had a dominant effect on the surface profile rather than the presence or absence of the fastening structures. Further, elevations were measured at the test site (Figure 1) to assess whether the fastening structures that tightly held the individual TPB blocks positively affected the minimization of settlement or subsidence. Figure 6 shows the difference in the elevation before and after one month of operation. The $\Delta$ elevation values for individual locations showed mostly settlement and some heaving, probably due to unexpected traffic movement. The extent of the difference was greater without the fastening structure, thus indicating the advantage of the fastening structure. In addition, the values of slip resistance measured as BPN were $34( \pm 5)$ and $33( \pm 2)$ for the WPF-RP TPB samples before and after one month of operation, respectively. These values satisfy the minimum slip resistance BPN values for road pavement materials under average conditions (S3) and for sections, where friction is not important (S4) at risk level 1. This level is defined as when there are few accidents due to road slipping or when accidents are not yet recorded (Ministry of Land, Infrastructure and Transport (MOLIT), 2016). The detailed definitions of minimum friction coefficient and risk are provided in Supplementary Tables S3, S4. This indicates that TPBs could be potentially applied to roads with low-speed driving, such as side roads, and those with minimal friction needs, such as on flat ground. 


\section{DISCUSSION}

Based on the mechanical characteristics of the WPF-RPs, the accelerated weathering test, road pavement vehicle stability, environmental assessment, and field tests for TPBs, we suggest two additional possible applications of WPF-RPs, as construction materials for pothole emergency repair and backfilling structures for underground buried pipes (Figure 7). Pothole emergency repair generally uses cold-mix asphalt repair materials. However, potholes formed during rainy season make it difficult to demonstrate the performance of emergency repair materials due to moisture on the road surface, and re-damage most likely occurs after repair (Byzyka et al., 2020). To ensure vehicle load resistance, rapid installation, and short-term use, WPF-RPs can be used for pothole emergency repair. An example of the application for emergency repair of $5 \mathrm{~cm}$ deep potholes using anchors is provided in Figure 7B. In addition, during road excavation restoration work for the maintenance of underground buried pipes, voids can occur at the beginning of common use because of poor compaction at the bottom of buried pipes; consequently, adjacent soils move into the voids. This results in overall settlement in the backfill soil along with faulting and distresses in the pavement of the excavation recovery site (Bae et al., 2017). To improve the backfilling and fastening structure of underground buried pipes during excavation recovery construction and to improve the compaction defect, the application of WPF-RPs is proposed, which could better address the accelerated weathering issues associated with light exposure.

In this study, WPF-RPs were used in recycled waste materials, such as TPBs, which were tested for basic mechanical properties, stability under external light exposure conditions and vehicle loads, and the presence of hazardous substances. The results indicated compressive strength of approximately $38 \mathrm{MPa}$, stable color, and tensile properties up to $1,500 \mathrm{~h}$ (or corresponding to $540 \mathrm{~d}$ ) of light exposure in accelerated weathering tests, and dynamic stability of 21,000-63,000 cycles/mm through wheel-tracking tests. Additionally, hazardous

\section{REFERENCES}

Aghaeipour, A., and Madhkhan, M. (2020). Mechanical properties and durability of roller compacted concrete pavement (RCCP) - a review. Road Mater. Pavement Design 21, 1775-1798. doi: 10.1080/14680629.2019.15 79754

Bae, Y. S., Kim, K. T., and Lee, S. Y. (2017). The road subsidence status and safety improvement plans. J. Korea Acad. Ind. Coop. Society 18, 545-552. doi: 10.5762/KAIS.2017.18. 1.545

Byzyka, J., Rahman, M., and Chamberlain, D. A. (2020). An improved interface temperature distribution in shallow hot mix asphalt patch repair using dynamic heating. Int. J. Pavement Eng. 21, 1617-1625. doi: 10.1080/10298436.2018.15 59315

Chung, S.-H., Na, J.-G., Kim, S.-G., Woo, H.-M., and Kim, Y.-T. (2013). Feedstock recycling technologies using waste vinyls. J. Korean Inst. Resour. Recycling 22, 46-54. doi: 10.7844/kirr.2013.22.4.46 substances were either not detected or under permissible limits in the composition and leachates of WPF-RPs during their application as construction materials, especially bearing loads. An assessment of the operation of WPF-RP TPBs in a field test for one month showed good stability for their temporary use in road construction. Further, the fastening structure could assist in load transferability and equalization between the installed TPBs installed. Moreover, other possible applications of WPF-RPs are suggested, such as in pothole emergency repair and backfilling structures for underground pipes. This study indicates that WPFs have potential applications as a recycling material and can be used as construction materials, and further field tests should be conducted to optimize their use.

\section{DATA AVAILABILITY STATEMENT}

The raw data supporting the conclusions of this article will be made available by the authors, without undue reservation.

\section{AUTHOR CONTRIBUTIONS}

DK and HO designed the research objective and developed the study with the support of SK and GM. DK collected, analyzed, interpreted the data, and wrote the first draft of the manuscript. HO, SK, and GM actively contributed to the final version. All authors approved the submitted version.

\section{FUNDING}

This study was supported by the Seoul Institute of Technology (SIT) research projects (2019-AA-011).

\section{SUPPLEMENTARY MATERIAL}

The Supplementary Material for this article can be found online at: https://www.frontiersin.org/articles/10.3389/frsus. 2021.756723/full\#supplementary-material
Dahlbo, H., Poliakova, V., Mylläri, V., Sahimaa, O., and Anderson, R. (2018). Recycling potential of post-consumer plastic packaging waste in Finland. Waste Manage. 71, 52-61. doi: 10.1016/j.wasman.2017.10.033

De Souza, L. C. (2019). SDG 12 - Initiatives to Reduce the Production and Consumption of Plastics. The Civil Society Report of Spotlight on Sustainable Development 2019. Available online at: https://www.2030spotlight.org/en/ book/1883/chapter/sdg-12-initiatives-reduce-production-and-consumptionplastics (accessed August 29, 2021).

Directive 2011/65/EU (2011). RoHS II Directive 2011/65/EU of the European Parliament and of the Council of 8 June 2011 on the Restriction of the Use of Certain Hazardous Substances in Electrical and Electronic Equipment (recast). Off. J. Eur. Union. 54, 174-88.

Gewert, B., Plassmann, M., Sandblom, O., and MacLeod, M. (2018). Identification of chain scission products released to water by plastic exposed to ultraviolet light. Environ. Sci. Technol. Lett. 5, 272-276. doi: 10.1021/acs.estlett.8b00119

Geyer, R., Jambeck, J. R., and Law, K. L. (2017). Production, use, and fate of all plastics ever made. Sci. Adv. 3:e1700782. doi: 10.1126/sciadv.1700782 
Hamad, K., Kaseem, M., and Deri, F. (2013). Recycling of waste from polymer materials: an overview of the recent works. Polym. Degrad. Stability 98, 2801-2812. doi: 10.1016/j.polymdegradstab.2013.09.025

Han, C.-G., Hwang, Y.-S., Lee, S.-H., and Kim, G.-D. (2003). Influence of admixture on the strength development of concrete at early age. J. Arch. Inst. Korea Struct. Constr. 19, 95-102.

Hopewell, J., Dvorak, R., and Kosior, E. (2009). Plastics recycling: challenges and opportunities. Philos. Trans. R. Soc. B 364, 2115-2126. doi: $10.1098 /$ rstb.2008.0311

Horodytska, O., Valdés, F. J., and Fullana, A. (2018). Plastic flexible films waste management - A state of art review. Waste Manage. 77, 413-425. doi: 10.1016/j.wasman.2018.04.023

Iñiguez, M. E., Conesa, J. A., and Fullana, A. (2018). Recyclability of four types of plastics exposed to UV irradiation in a marine environment. Waste Manage. 79, 339-345. doi: 10.1016/j.wasman.2018.08.006

Jang, Y.-C., Lee, G., Kwon, Y., Lim, J., and Jeong, J. (2020). Recycling and management practices of plastic packaging waste towards a circular economy in South Korea. Resour. Conserv. Recycling 158:104798. doi: 10.1016/j.resconrec.2020.104798

Joo, W. H., and Yeo, W. H. (2020). A study on the operation conditon of effective energy recovery and greenhouse gas reduction by the facility using waste / biomass fuel. J. Korea Org. Resour. Recycling Assoc. 28, 83-95. doi: 10.17137/korrae.2020.28.1.83

Kim, B. J., Kim, Y. C., Park, J. Y., and Jeong, J. H. (2013). Physical properties of asphalt concrete using wasted vinyl aggregates. J. Korean Society Road Eng. 15, 73-81. doi: 10.7855/IJHE.2013.15.2.073

Kim, T. H., Lee, J. U., and Hong, J.-Y. (2020). Production of recycled plastic film-based aggregates for use in concrete. Polym. Sci. Technol. 31, 478-483.

Korea Institute of Construction and Technology (KICT). (2018). Development of Pavement Material Conversion Technology from Waste Resources for Environmental Virtuous Circle. Goyang: KICT. 2018-2157.

Korean Industrial Standards, KS A 0063: 2015. (2015). Plastics - Method for Specification of Colour Differences for Opaque Materials. Seoul: Korean Standards Association.

Korean Industrial Standards, KS F 2274: 2018. (2018). Recommended Practice for Accelerated Artificial Exposure of Plastic Building Materials. Seoul: Korean Standards Association.

Korean Industrial Standards, KS F 2374: 2017. (2017). Standard Test Method for Wheel Tracking of Asphalt Mixtures. Seoul: Korean Standards Association.

Korean Industrial Standards, KS F 2375. (2016). Standard Test Method for Measuring Surface Frictional Properties Using the British Pendulum Tester. Seoul: Korean Standards Association.

Korean Industrial Standards, KS M ISO 11359-2. (2017). Plastics Thermomechanical Analysis (TMA) - Part 2: Determination of Coefficient of Linear Thermal Expansion and Glass Transition Temperature. Seoul: Korean Standards Association.

Korean Industrial Standards, KS M ISO 1183-1. (2019). Plastics - Methods for Determining the Density of Non-Cellular Plastics - Part 1: Immersion Method, Liquid Pycnometer Method and Titration Method. Seoul: Korean Standards Association.

Korean Industrial Standards, KS M ISO 527. (2017). Plastics - Determination of Tensile Properties. Seoul: Korean Standards Association.

Korean Industrial Standards, KS M ISO 527-2. (2018). Plastics - Determination of Tensile Properties - Part 2: Test Conditions for Moulding and Extrusion Plastics. Seoul: Korean Standards Association.

Korean Industrial Standards, KS M ISO 604. (2018). Plastics - Determination of Compressive Properties. Seoul: Korean Standards Association.

Lam, M. N.-T., Le, D.-H., and Jaritngam, S. (2018). Compressive strength and durability properties of roller-compacted concrete pavement containing electric arc furnace slag aggregate and fly ash. Constr. Build. Mater. 191, 912-922. doi: 10.1016/j.conbuildmat.2018.10.080

Lim, J. S., Son, S. C., Liu, J. H., and Jeong, J. H. (2010). Modeling of friction characteristic between concrete pavement slab and subbase. J. Korean Soc. Road Eng. 12, 211-218.

Meys, R., Frick, F., Westhues, S., Sternberg, A., and Klankermayer, J. (2020). Towards a circular economy for plastic packaging wastes - the environmental potential of chemical recycling. Resour. Conserv. Recycling 162:105010. doi: 10.1016/j.resconrec.2020.105010
Ministry of Environment (MOE). (1992). Act on the Promotion of Saving and Recycling of Resources. 1992/4538/Korea.

Ministry of Environment (MOE). (2017). Korean Official Wastes Test Method, Korea.

Ministry of Environment (MOE). (2019). Act on Resource Circulation of Electrical and Electronic Equipment and Vehicles. 2019/15657/Korea.

Ministry of Environment (MOE). (2020a). Current status of waste generation and treatment throughout the country in 2019. Korea.

Ministry of Environment (MOE). (2020b). Project for development of a recycling molding system using waste synthetic resins and others. RひD. 2018000710003.

Ministry of Land, Infrastructure and Transport (MOLIT) (2016). Guidelines for Installation and Management of Road Safety Facilities -Skid Resistance Pavement, Korea.

Ministry of Land, Infrastructure and Transport (MOLIT) (2017). Guideline for Asphalt Concrete Pavement Construction, Korea.

Ministry of Trade, Industry and Energy (MOTIE) (2019) Act on the Promotion of the Development, Use and Diffusion of New and Renewable Energy. 2019/16236/Korea.

Mokrzycki, W. S., and Tatol, M. (2011). Colour difference $\Delta \mathrm{E}$ - a survey. Mach. Graphic Vis. 20, 383-411.

Noguchi, T., Tomosawa, F., Nemati, K. M., Chiaia, B. M., and Fantilli, A. P. (2009). A practical equation for elastic modulus of concrete. ACI Struct. J. 8, 690-696.

Park, H. W., Shim, C. S., Lim, J. S., Joe, N. H., and Jeong, J. H. (2017) Development of three-dimensional finite element model for structural analysis of airport concrete pavements. Int. J. Highw. Eng. 19, 67-74. doi: 10.7855/IJHE.2017.19.6.067

PlasticsEurope. (2020). Plastics - the Facts 2020: An analysis of European plastics production, demand and waste data. Available online at: https://www. plasticseurope.org/application/files/8016/1125/2189/AF_Plastics_the_factsWEB-2020-ING_FINAL.pdf (accessed August 29, 2021).

Rahimi, A., and García, J. M. (2017). Chemical recycling of waste plastics for new materials production. Nat. Rev. Chem. 1:0046. doi: 10.1038/s41570-0170046

Ryan, P. G. (2015). "A brief history of marine litter research," in Marine Anthropogenic Litter, eds M. Bergmann, L. Gutow, and M. Klages. Cham: Springer. 1-25. doi: 10.1007/978-3-319-165103_1

Shah, A. A., Hasan, F., and Hameed, A., and Ahmed, S. (2008). Biological degradation of plastics: a comprehensive review. Biotechnol. Adv. 26, 246-265. doi: 10.1016/j.biotechadv.2007.12.005

Shen, L., Worrell, E., and Patel, M. K. (2010). Open-loop recycling: a LCA case study of PET bottle-to-fibre recycling. Resour. Conserv. Recycling 55, 34-52. doi: 10.1016/j.resconrec.2010.06.014

UN (2016). The Sustainable Development Agenda. Available online at: http://www. un.org/sustainabledevelopment/development-agenda/ (accessed September 25, 2015).

Yeom, W. S., An, G. H., Liu, J. H., and Jeong, J. H. (2014). Thermal characteristics of cement concrete mixed with wasted vinyl aggregates. Int. J. Highw. Eng. 16, 79-86. doi: 10.7855/IJHE.2014.16.6.079

You, T., and Sim, J. (2006). Sensitivity analysis of 3-dimensional FE models for jointed concrete pavements. J. Korean Society Civil Eng. 26, 435-444.

Conflict of Interest: The authors declare that the research was conducted in the absence of any commercial or financial relationships that could be construed as a potential conflict of interest.

Publisher's Note: All claims expressed in this article are solely those of the authors and do not necessarily represent those of their affiliated organizations, or those of the publisher, the editors and the reviewers. Any product that may be evaluated in this article, or claim that may be made by its manufacturer, is not guaranteed or endorsed by the publisher.

Copyright (c) $2021 \mathrm{Ki}$, Kang, Ma and Oh. This is an open-access article distributed under the terms of the Creative Commons Attribution License (CC BY). The use, distribution or reproduction in other forums is permitted, provided the original author(s) and the copyright owner(s) are credited and that the original publication in this journal is cited, in accordance with accepted academic practice. No use, distribution or reproduction is permitted which does not comply with these terms. 